Original Research

\title{
Ankle Fractures and Modality of Hospital Transport at a Single Level 1 Trauma Center: Does Transport by Helicopter or Ground Ambulance Influence the Incidence of Complications?
}

\author{
Sarah E. Greenberg, BA ${ }^{1}$, Rivka C. Ihejirika, BS ${ }^{2}$, Vasanth Sathiyakumar, BA ${ }^{2}$, \\ Maximilian F. Lang, BS ${ }^{2}$, Dagoberto Estevez-Ordonez, BS ${ }^{2}$, Marc A. Prablek, BS ${ }^{2}$, \\ Alexander Y. Chern, BS ${ }^{2}$, Rachel V. Thakore, BS ${ }^{1}$, William T. Obremskey, MD, MPH, MMHC ${ }^{3}$, \\ David Joyce, $\mathrm{MD}^{4}$, Manish K. Sethi, MD ${ }^{4}$ \\ ${ }^{1}$ Health Policy Fellow, The Vanderbilt Orthopaedic Institute Center for Health Policy, Vanderbilt University, Nashville, TN \\ ${ }^{2}$ Medical Student, The Vanderbilt Orthopaedic Institute Center for Health Policy, Vanderbilt University, Nashville, TN \\ ${ }^{3}$ Surgeon and Professor, The Vanderbilt Orthopaedic Institute Center for Health Policy, Vanderbilt University, Nashville, TN \\ ${ }^{4}$ Surgeon and Assistant Professor, The Vanderbilt Orthopaedic Institute Center for Health Policy, Vanderbilt University, Nashville, TN
}

\section{A R T I C L E I N F O}

Level of Clinical Evidence: 4

Keywords:

ambulance

complication

emergency transportation

GEMS

HEMS

injury

\begin{abstract}
A B S T R A C T
In an era of concern over the rising cost of health care, cost-effectiveness of auxiliary services merits careful evaluation. We compared costs and benefits of Helicopter Emergency Medical Service (HEMS) with Ground Emergency Medical Service (GEMS) in patients with an isolated ankle fracture. A medical record review was conducted for patients with an isolated ankle fracture who had been transported to a level 1 trauma center by either HEMS or GEMS from January 1, 2000 to December 31, 2010. We abstracted demographic data, fracture grade, complications, and transportation mode. Transportation costs were obtained by examining medical center financial records. A total of 303 patients was included in the analysis. Of 87 (28.71\%) HEMS patients, 53 (60.92\%) had sustained closed injuries and 34 (39.08\%) had open injuries. Of the 216 (71.29\%) GEMS patients, $156(72.22 \%)$ had closed injuries and $60(27.78 \%)$ had open injuries. No significant difference was seen between the groups regarding the percentage of patients with open fractures or the grade of the open fracture $(p=.07)$. No significant difference in the rate of complications was found between the 2 groups $(p=18)$. The mean baseline cost to transport a patient via HEMS was $\$ 10,220$ + a $\$ 108 /$ mile surcharge, whereas the mean transport cost using GEMS was $\$ 976$ per patient $+\$ 16 /$ mile. Because the HEMS mode of emergency transport did not significantly improve patient outcomes, health systems should reconsider the use of HEMS for patients with isolated ankle fractures.
\end{abstract}

(c) 2015 by the American College of Foot and Ankle Surgeons. All rights reserved.
In 2010 in the United States, use of the Helicopter Emergency Medical Service (HEMS) cost $\$ 240$ million more than the use of Ground Ambulance Emergency Medical Service (GEMS) yet transported substantially fewer patients (1). Individual institutions spent $\$ 115,777$ to $\$ 5.5$ million annually on HEMS (2). As the U.S. health care system strives to reduce costs, tertiary care centers face increased financial pressures to further reduce expenditures. One factor

\footnotetext{
Financial Disclosure: None reported.

Conflict of Interest: William T. Obremskey has previously consulted for biometrics, given expert testimony in legal matters, was committee chair of the OTA and SEFC, and has a grant from the Department of Defense (grant no. W81XWH-10-20133). For the remaining authors, no conflicts of interest were declared.

Address correspondence to: Manish K. Sethi, MD, Vanderbilt Orthopaedic Institute Center for Health Policy, Vanderbilt University, Suite 4200, South Tower, MCE, Nashville, TN 37221.

E-mail address: Manish.Sethi@Vanderbilt.edu (M.K. Sethi).
}

affecting the cost of treating patients with ankle fractures is the mode of emergency transportation to a medical facility. Several studies have found decreased rates of morbidity and mortality in patients with severe injuries or profound autonomic instability or who were located in remote locations with limited resources (3-6) when HEMS is used for transportation. Other studies, in contrast, have demonstrated no significant differences in outcomes between patients who were transported by HEMS as opposed to GEMS $(2,7)$.

Given that ankle fractures are one of the most prevalent joint injuries-with a reported incidence of 187 per 100,000 Americans annually - the issue of using HEMS for the transport of patients with this type of injury is especially important as an avenue to reducing costs (8). No study to date has investigated whether complication rates in patients with ankle fractures differ according to the mode of transport. However, because nearly 600,000 Americans sustain ankle fractures annually, using the most cost-effective method of 
transportation could be an avenue toward decreasing overall health care costs (8).

In the present retrospective cohort study, we evaluated the outcomes related to the emergency transport of patients with isolated ankle fractures to a single level I tertiary trauma center. By exploring the relationship between the method of transport and the incidence of complications, we aimed to determine whether the incidence of complications varied with the method of transportation. As a secondary aim, we undertook a crude cost comparison between the 2 transportation methods.

\section{Patients and Methods}

The Vanderbilt Institutional Review Board (IRB) approved the present study. We then identified all patients who had sustained ankle fractures and had been treated at our level I trauma center from January 1, 2000 to January 1, 2010, using a Common Procedural Terminology code search of the institution's orthopedic database (codes 27766, 27784, 27792, 27814, 27822, 27823, 27829, and 27822). All medical records were reviewed to find those patients who had sustained isolated ankle fractures. Patients who had presented with any other injuries, such as organ damage, or those with other medical conditions were excluded from the present study. For these patients with an isolated ankle fracture, the electronic medical records were reviewed further to collect demographic variables, such as age, gender, and American Society of Anesthesiologists physical status classification (9-12), type of fracture (open or closed) $(13,14)$, and the modality of transport (HEMS or GEMS) used to get the patient to the trauma center. Patients transported by other means were excluded. Additionally, using the Gustilo-Anderson classification, open fractures were further classified regarding fracture grade (grade I to III) $(13,14)$. Any complication after the initial treatment that led to reoperation or readmission was identified. Postoperative complications were separated into nonunion, infection, painful hardware, and hardware failure. We performed a multivariate analysis. These authors gathered all medical record data (V.S., R.V.T., R.C.I., M.F.L., D.E.-O., M.A.P., A.Y.C.). Fracture grade was reported within the patient chart. The grade of the fracture was considered in the context of a multivariate analysis when evaluating the complications and costs for ankle fractures according to transportation method.

Financial data for determining transport costs was obtained from our university's financial services. The specific costs used in the present study were calculated from the technical and direct costs of transportation as given in the patient's financial record. These costs were summed to determine the overall cost of transportation. The mean mileage costs for HEMS and GEMS were determined by dividing the overall cost of transportation by the distance travelled. Statistical analyses comparing clinical data and costs between the 2 groups were conducted using Fisher's exact test, correlated statistics, and independent samples Student's $t$ tests.

\section{Results}

A total of 887 patients with ankle fractures were identified by our initial Common Procedural Terminology code search, of whom 439 (49.5\%) had sustained isolated ankle fractures. Of these patients, 303 (69.0\%) had been transported by either HEMS or GEMS and were included in our analyses. Specifically, 87 patients (28.7\%) had been transported by HEMS and 216 (71.3\%) by GEMS.

The demographic variables for the 2 transportation groups are listed in Table 1. No statistically significant differences were found between the 2 groups with respect to mean age, American Society of Anesthesiologists score, or the prevalence of open ankle fracture. Of the patients with open fractures, $4(11.8 \%)$ in the HEMS group had grade 1 open fractures, 8 (23.5\%) had grade 2, and $22(64.7 \%)$ had grade 3 compared with 8 patients $(13.3 \%)$ in the GEMS group with grade 1 fractures, 23 (38.3\%) with grade 2, and 29 (48.3\%) with grade 3 fractures $(p=.28)$. There were statistically significantly more males in the HEMS group $(p=.28)$.

The incidence of complications for the 2 transportation groups are listed in Table 2. A total of 27 patients (8.9\%) developed complications. Of these 27 patients, 11 (12.64\%) were transported by HEMS and 16 (7.4\%) were transported by GEMS. No statistically significant differences were identified in the overall incidence of complications between the 2 groups ( $p=.18$ ) or when the comparisons were stratified by the different types of complications.
Table 1

Comparison of demographic variable by transportation group $(\mathrm{N}=303$ patients $)$

\begin{tabular}{llll}
\hline Variable & HEMS $(\mathrm{n}=87)$ & GEMS $(\mathrm{n}=216)$ & $p$ Value $^{*}$ \\
\hline $\begin{array}{l}\text { Age }(\mathrm{y}) \\
\text { Gender }\end{array}$ & $41.9 \pm 16.1$ & $42.7 \pm 16.6$ & .71 \\
Male & $56(64.37)$ & $106(49.07)$ & .02 \\
Female & $31(35.63)$ & $110(50.93)$ & \\
ASA score & $2.23 \pm 0.74$ & $2.27 \pm 0.66$ & .66 \\
Open fracture & $34(39.08)$ & $60(27.78)$ & .07 \\
Yes & $53(60.92)$ & $156(72.22)$ & \\
No & & & \\
\hline
\end{tabular}

Abbreviations: ASA, American Society of Anesthesiologists; GEMS, ground emergency medical service; HEMS, helicopter emergency medical service. Data presented as mean \pm standard deviation or $n$ (\%).

* Fisher's exact test or independent samples Student's $t$ test.

The baseline transportation costs between HEMS and GEMS and the aggregate costs of transportation taking into account all the patients in each group are compared in the Fig. The baseline costs for HEMS were $\$ 10,220$ plus $\$ 108 /$ mile. The baseline costs for GEMS were $\$ 976$ plus $\$ 16 /$ mile. Because the distance traveled was not regularly reported in the patients' medical records, we calculated the aggregate costs and per capita costs from the baseline rates, excluding the mileage surcharge. The aggregate cost for the 87 HEMS patients was $\$ 889,140$ compared with $\$ 210,816$ for the 216 GEMS patients (Fig.). With respect to the per capita transportation costs for a patient with an isolated ankle fracture, HEMS cost about $\$ 10,220$, whereas GEMS cost approximately $\$ 976$, a difference of $>\$ 9000$ per patient. Fewer patients $(n=87)$ were transported by HEMS than were transported by GEMS $(n=216)$, a statistically significant difference $(p=.004)$.

\section{Discussion}

It is important to note that in general, trauma patients who are transported by HEMS match specific criteria based on age, vital signs, severity of injury, and proximity to a trauma center that cause emergency services to recommend air transportation $(15,16)$. The decision to use HEMS is also dependent upon policies created by the local and regional health care environment (16). Therefore, the patients with isolated ankle fractures who were transported by HEMS fulfilled the requirements needed for air transportation as determined by the specific region. Our study evaluated isolated ankle fracture patients as opposed to multi-trauma patients with ankle fractures, therefore our results demonstrated the correlation directly between ankle fractures and transportation without being confounded by higher mortality and complication rates caused by associated injuries (17-21). Note that, in general, trauma patients who are transported by HEMS must match specific criteria regarding age, vital signs, severity of injury (e.g., neurovascular compromise), and proximity to a trauma center in order for emergency services to recommend air transportation (15). Patients with isolated ankle fractures who were transported by HEMS fulfilled the requirements needed for air

\section{Table 2}

Incidence of complications stratified by transportation group ( $\mathrm{n}=27$ complications)

\begin{tabular}{lccl}
\hline Complication & HEMS $(\mathrm{n}=11)$ & GEMS $(\mathrm{n}=16)$ & $p$ Value $^{*}$ \\
\hline Nonunion & $3(27.3)$ & $4(25.0)$ & .99 \\
Infection & $3(27.3)$ & $5(31.3)$ & .99 \\
Painful hardware & $5(45.5)$ & $5(31.3)$ & .69 \\
Hardware failure & 0 & $2(12.5)$ & .49 \\
Total & $11(100)$ & $16(100)$ & .18 \\
\hline
\end{tabular}

Abbreviations: GEMS, ground emergency medical service; HEMS, helicopter emergency medical service.

* Fisher's exact test or independent samples Student's $t$ tests. 

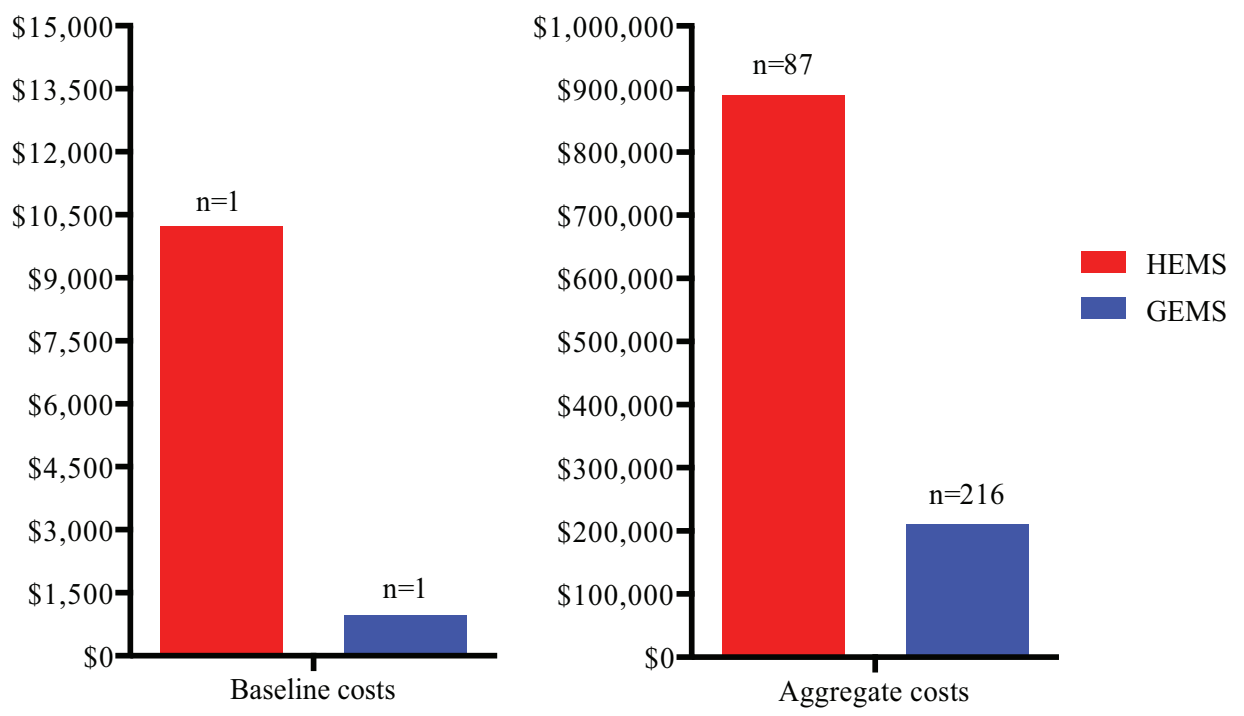

Fig. Comparison of baseline and aggregate costs. Note: Baseline scale $66.67 \%$ of aggregate.

transportation by presenting with neurovascular injuries, vascular injuries, or the inability to reduce the ankle fracture or dislocation in the field. However, because our study evaluated patients with isolated ankle fracture instead of multitrauma patients with ankle fractures, our results have demonstrated the correlation directly between ankle fractures and transportation without a bias from greater mortality and complication rates caused by the associate injuries (17 21). Ours is the first retrospective study to demonstrate that the incidence of postoperative complications in patients with isolated ankle fractures does not significantly differ according to the method of transportation. Furthermore, we demonstrated that, from a cost standpoint, HEMS results in significantly greater costs $(\$ 889,000$ per 87 patients) compared with GEMS (\$211,000 per 216 patients) while transporting a significantly fewer number of patients (87 versus 216; $p=.004)$ (crude cost analysis).

Relatively few studies have evaluated the effectiveness of HEMS for orthopedic injuries. In a study focusing on 274 patients with spinal injuries who were transported by either HEMS or GEMS, Foster et al (22) found no significant differences in in-hospital mortality, hospital length of stay, or overall discharge according to the method of transportation. In the 2010 study by Ozer et al (23), investigating 40 patients with finger amputations, the decreased transportation time using HEMS did not affect the successful reimplantation of digits. The results of this investigation are similar to the aforementioned studies in that no improvement in patient outcomes was achieved by using of HEMS instead of GEMS.

For patients with multitrauma, the few studies exploring HEMS in the orthopedic trauma population, including ours, have all focused on isolated injuries (spine, digits, and ankles). Multiple studies have found benefits in patient outcomes using HEMS for nonisolated injury cases. For example, in a retrospective study by Shatney et al (24), patients with an injury severity score $>9$ benefitted from HEMS because of the reduced transit time compared with patients with a lower injury severity score, who were more likely to be discharged. A study by Thomas et al (25) of blunt trauma patients also demonstrated that patients with polytraumatic injuries have increased rates of survival when transported by HEMS compared with GEMS. Furthermore, studies have demonstrated that HEMS is more frequently staffed with highly trained personnel, including physicians and critical care specialists, who are of greater benefit to patients with multiple injuries (26-29). It is therefore interesting to compare the results of studies focusing on isolated fractures with those of studies of patients with more generalized injuries, in which HEMS has been proved to have advantages in providing care and reducing the transit time for severely injured patients (30).

From a cost perspective, Delgado et al (1) determined that HEMS must cost $<\$ 100,000$ per quality-adjusted life-year compared with GEMS to meet cost-effective goals. Taylor et al (2) performed a systematic review of 15 studies to investigate the cost-effectiveness of HEMS and found that 5 studies had increased costs with helicopter transport without improvement in outcomes. In contrast, the investigators found 8 studies in which HEMS was both cost-effective and provided improvement in patient outcomes. Another study by Taylor et al (29) found that HEMS is more likely to be cost-effective for patients with serious injuries, in particular traumatic brain injuries. In our study, we found significantly greater costs without improvements in the incidence of complications for patients transported by HEMS. Although our study did not longitudinally monitor patients to calculate the cost per life saved or cost per life-year saved, we nevertheless questioned the correlation between costs and patient outcomes for HEMS compared with GEMS from our cost comparison results. HEMS might be more costeffective in patients with ankle fracture and concurrent injuries, such as was suggested by the results from the study by Taylor et al (29).

Our study had limitations. First, our cost calculations were limited to the baseline costs for HEMS versus GEMS. Considering the discrepancy in the additional per-mile costs between the 2 transportation methods, this would have been important to calculate to determine the true discrepancy in the costs. Our cost calculations were also limited, because we did not evaluate the quality of life units in regard to the cost of care and, therefore, transportation. Without the consideration of quality-adjusted life units and incremental costs differences, we could not truly perform a cost-effectiveness analysis of HEMS versus GEMS; however, direct cost comparisons are essential to highlight specific correlations and drive future investigations into such hypotheses. Our study specifically measured the cost of transportation, without consideration of the distance transported, for patients with isolated ankle fractures. Finally, to further elucidate the differences between HEMS and GEMS, it would be beneficial to analyze other factors such as nonorthopedic-related complications and the location of the patients, because remote regions differ in their access to transportation compared with more urban regions.

In conclusion, despite these limitations, our study has provided evidence that for isolated ankle fractures, HEMS is not significantly associated with fewer complications but is associated with substantially greater costs. In contrast, transportation by GEMS resulted in 
significantly lower transportation costs without increasing the risk of complications. Therefore, with respect to our study, GEMS should be considered a valuable transportation method for patients with isolated ankle fractures. Nevertheless, additional research is necessary to identify the risk factors associated with ankle fractures that might benefit from transportation by HEMS instead of GEMS. The results of our investigation could be used in the development of future randomized controlled trials and prospective cohort studies focusing on emergency transportation of patients with ankle fractures.

\section{References}

1. Delgado MK, Staudenmayer KL, Wang NE, Spain DA, Weir S, Owens DK, Goldhaber-Fiebert JD. Cost-effectiveness of helicopter versus ground emergency medical services for trauma scene transport in the United States. Ann Emerg Med 62:351-364.e19, 2013.

2. Taylor CB, Stevenson M, Jan S, Middleton PM, Fitzharris M, Myburgh JA. A systematic review of the costs and benefits of helicopter emergency medical services. Injury 41:10-20, 2010.

3. Berlot G, La Fata C, Bacer B, Biancardi B, Viviani M, Lucangelo U, Gobbato P, Torelli L, Carchietti E, Trillò G, Daniele M, Rinaldi A. Influence of prehospital treatment on the outcome of patients with severe blunt traumatic brain injury: a single-centre study. Eur J Emerg Med 16:312-317, 2009.

4. McVey J, Petrie DA, Tallon JM. Air versus ground transport of the major trauma patient: a natural experiment. Prehosp Emerg Care 14:45-50, 2010.

5. Mitchell AD, Tallon JM, Sealy B. Air versus ground transport of major trauma patients to a tertiary trauma centre: a province-wide comparison using TRISS analysis. Can J Surg 50:129-133, 2007.

6. Sullivent EE, Faul M, Wald MM. Reduced mortality in injured adults transported by helicopter emergency medical services. Prehosp Emerg Care 15:295-302, 2011.

7. Talving P, Telxeira PG, Barmparas G, DuBose J, Inaba K, Lam L, Demetriades D. Helicopter evacuation of trauma victims in Los Angeles: does it improve survival? World J Surg 33:2469-2476, 2009.

8. Daly PJ, Fitzgerald RH Jr, Melton LJ, Ilstrup DM. Epidemiology of ankle fractures in Rochester, Minnesota. Acta Orthop Scand 58:539-544, 1987.

9. American Society of Anesthesiologists. ASA Physical Status Classification System. Available at: https://www.asahq.org/clinical/physicalstatus.htm. Accessed November 7, 2014.

10. Owens WD, Felts JA, Spitznagel EL Jr. ASA physical status classifications: a study of consistency of ratings. Anesthesiology 49:239-243, 1978.

11. Daabiss M. American Society of Anesthesiologists physical status classification. Indian J Anaesth 55:111-115, 2011.

12. McDonald MR, Sathiyakumar V, Apfeld JC, Hooe B, Ehrenfeld J, Obremskey WT, Sethi MK. Predictive factors of hospital length of stay in patients with operatively treated ankle fractures. J Orthop Traumatol 15:255-258, 2014.
13. Gustilo RB, Simpson L, Nixon R. Analysis of 511 open fractures. Clin Orthop Relat Res 66:149-154, 1969.

14. Sprint Investigators. Prognostic factors for predicting outcomes after intramedullary nailing of the tibia. J Bone Joint Surg 94:1786-1793, 2012.

15. Association of Air Medical Services. Position paper on the appropriate use of emergency air medical services. J Air Med Transp 9:29-30, 1990.

16. Appropriate and Safe Utilization of Helicopter Emergency Medical Services. American College of Emergency Physicians, 2011. Available at:Available at: http:// www.acep.org/Clinical-Practice-Management/Appropriate-and-Safe-Utilizationof-Helicopter-Emergency-Medical-Services/. Accessed March 24, 2015.

17. Hebert JS, Burnham RS. The effect of polytrauma in persons with traumatic spine injury: a prospective database of spine fractures. Spine 25:55-60, 2000.

18. Baker SP, O’Neill B. The injury severity score: an update. J Trauma 16:882-885, 1976.

19. Baker SP, O'Neill B, Haddon W, Long WB. The injury severity score: a method of describing patients with multiple injuries and evaluating emergency care. J Trauma 14:187-196, 1974.

20. Hill DA, Abraham KJ, West RH. Factors affecting outcome in the resuscitation of severely injured patients. Aust N Z J Surg 63:604-609, 1994.

21. Kafie KF, Tominaga GT, Yoong B, Waxman K. Factors related to outcome in blunt intestinal injuries requiring operation. Am Surg 63:889-892, 1997.

22. Foster NA, Elfenbein DM, Kelley W Jr, Brown CR, Foley C, Scarborough JE, Vaslef SN, Shapiro ML. Comparison of helicopter versus ground transport of the interfacility transported of isolated spine injury. Spine J 14:1147-1150, 2014.

23. Ozer K, Kramer W, Gillani S, Williams A, Smith W. Replantation versus revision of amputated fingers in patients air-transported to a level I trauma center. J Hand Surg Am 35:936-940, 2012.

24. Shatney $\mathrm{CH}$, Homan SJ, Sherck JP, Ho CC. The utility of helicopter transport of trauma patients from the injury scene in an urban trauma system. J Trauma 53:817-822, 2002.

25. Thomas SH, Harrison TH, Buras WR, Ahmed W, Cheema F, Wedel SK. Helicopter transport and blunt trauma mortality: a multicenter trial. J Trauma 52:136-145, 2002.

26. Butler DP, Anwar I, Willett K. Is it the H or the EMS in HEMS that has an impact on trauma patient mortality: a systematic review of the evidence. Emerg Med J 27:692-701, 2010

27. Garner AA. The role of physician staffing of helicopter emergency medical services in prehospital trauma response. Emerg Med Australas 16:318-323, 2004.

28. Ringburg AN, Thomas SH, Steyerberg EW, van Lieshout EM, Patka P, Schipper IB Lives saved by helicopter emergency medical services: an overview of literature. Air Med J 28:298-302, 2009.

29. Taylor C, Jan S, Curtis K, Tzannes A, Li Q Palmer C, Dickson C, Myburgh J. The cost-effectiveness of physician helicopter emergency medical service (HEMS) transport to a major trauma centre in NSW, Australia. Injury 43:1843-1849, 2012.

30. Biewener A, Aschenbrenner U, Rammelt S, Grass R, Zwipp H. Impact of helicopter transport and hospital level on mortality of polytrauma patients. J Trauma 56:94-98, 2004. 